\title{
Low-Internal-Stress Nickel Multiwalled Carbon Nanotube Composite Electrodeposited from a Sulfamate Bath
}

\author{
Susumu Arai, ${ }^{a, *, z}$ Takashi Saito, ${ }^{a}$ and Morinobu Endo ${ }^{b}$ \\ ${ }^{a}$ Department of Chemistry and Material Engineering, and ${ }^{b}$ Department of Electrical and Electronic \\ Engineering, Faculty of Engineering, Shinshu University, Nagano 380-8553, Japan
}

\begin{abstract}
Nickel multiwalled carbon nanotube (MWCNT) composite plating was studied using a sulfamate-based bath. The effects of additives, current density, and bath temperature on the microstructure of Ni-MWCNT composite films were examined. The content of MWCNTs and internal stress of the composite films were also investigated. The addition of both sodium saccharin dihydrate and 2-butyne-1,4-diol caused a decrease in the voids formed in the composite films. The amount of voids in the composite films increased with increasing bath temperature. A Ni-MWCNT composite film with 0.4 mass \% MWCNTs, no significant voids, and low internal stress was fabricated by adjusting the bath composition and electrodeposition conditions. (C) 2007 The Electrochemical Society. [DOI: 10.1149/1.2768285] All rights reserved.
\end{abstract}

Manuscript submitted March 29, 2007; revised manuscript received June 11, 2007. Available electronically August $14,2007$.

Carbon nanotubes $(\mathrm{CNTs})^{1,2}$ have excellent mechanical characteristics such as high tensile strength and high elastic modulus. They also have high thermal and electrical conductivity. Thus, research into practical applications of CNTs, such as the preparation of resinCNT, ceramic-CNT, and metal-CNT composites, has been actively pursued.

Recently, the fabrication of metal-CNT composites has been attempted by an electrodeposition technique. The tribological behavior of Ni-multiwalled CNT (Ni-MWCNT) composite coatings ${ }^{3,4}$ and $\mathrm{Ni}-\mathrm{Co}-\mathrm{CNT}$ composite coatings ${ }^{5}$ fabricated by electrodeposition has been reported. Chen et al. ${ }^{6}$ have also reported the corrosion behavior of Ni-CNT composite coatings. This work indicated that the incorporation of CNTs into the nickel coating significantly increased the corrosion resistance.

The present authors and others have reported the fabrication of $\mathrm{Cu}-\mathrm{MWCNT}$ composite films and $\mathrm{Cu}$-cup-stacked CNT composite films by an electrodeposition technique. ${ }^{7,8}$ We have also reported that $\mathrm{Cu}-\mathrm{MWCNT}$ composite powder materials with a sea urchin shape $^{9}$ and Ni-MWCNT composite powder materials with a skewered dumpling shape ${ }^{10}$ were formed using the electrodeposition technique. Furthermore, we have reported that Ni-MWCNT composite film showed excellent thermal conductivity ${ }^{11}$ when a socalled Watts bath was used as the base bath. To extend the practical application of the Ni-MWCNT composite plating technology, control of the internal stress in Ni-MWCNT composites is important. Internal stress causes peeling of the plated film or warping of the substrate; therefore, lowering of the internal stress is desirable. Generally, a sulfamate bath has been used to obtain stress-free nickelplated films.

In the present study, we examined Ni-MWCNT composite plating using a sulfamate bath as the base plating bath. The effects of additives and the electrodeposition conditions on the microstructure and internal stress of the composite films were investigated.

\section{Experimental}

The CNTs used in the present study were commercially available (Showa Denko Co. Ltd.) vapor-grown MWCNTs, obtained via catalyst-assisted chemical vapor deposition (CVD) ${ }^{12}$ and heattreated at $2800^{\circ} \mathrm{C}$ in $\mathrm{Ar}$ for $30 \mathrm{~min}$. The MWCNTs were typically $100-200 \mathrm{~nm}$ in diameter and $10-20 \mu \mathrm{m}$ in length. A sulfamate Niplating bath $\left[1 \mathrm{~mol} \mathrm{dm}^{-3} \mathrm{Ni}\left(\mathrm{SO}_{3} \mathrm{NH}_{2}\right)_{2}+0.5 \mathrm{~mol} \mathrm{dm}^{-3} \mathrm{H}_{3} \mathrm{BO}_{3}\right]$ was used as the base bath. The MWCNTs did not disperse uniformly in the base bath; therefore, a homogeneous dispersion of MWCNTs was achieved by the addition of a polyacrylic acid (PA5000, mean molecular weight 5000) dispersant to the base bath with stirring. Sodium saccharin dihydrate (SA) and 2-butyne-1,4-diol (BD) were

\footnotetext{
* Electrochemical Society Active Member.

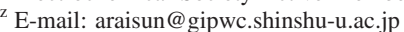

also added to the plating bath. Plating was performed at $25^{\circ} \mathrm{C}$ with aeration under galvanostatic conditions. A commercially available electrolytic cell (Microcell model I, Yamamoto-Ms Co., Ltd.) with internal dimensions of $65 \times 65 \times 95 \mathrm{~mm}$ was employed for electrodeposition. The volume of the plating bath was $250 \mathrm{~cm}^{3}$. A pure copper plate with an exposed surface area of $10 \mathrm{~cm}^{2}$ (3 $\times 3.33 \mathrm{~cm}$ ) was used as the substrate. A nickel plate containing a small amount of sulfur (Sumitomo SK nickel) was used as the anode.

The content of MWCNTs in the composite films was weighed directly. For the weight measurement, thick Ni-MWCNT composite films (over $8 \mathrm{~g}$ ) were electrodeposited. Subsequently, the nickel matrix of the composite films was dissolved in hot nitric acid. Then, the MWCNTs in the nitric acid solution were filtrated, dried, and weighed. The Ni-MWCNT composite films were examined using field-emission scanning electron microscopy (FE-SEM; JEOL JSM7000F). The exclusive sample-preparation equipment (cross-section polisher; JEOL SM-09010) was used to prepare cross-sectional samples for observation. The internal stress was measured using a deposit stress analyzer (Specialty Testing and Development 683EC Analyzer). The total electricity of the electrodeposits for the internal stress measurements was $60 \mathrm{C} \mathrm{cm}^{-2}$

\section{Results and Discussion}

Figure 1 shows the surface (a) and cross-sectional SEM images (b) of an electrodeposit from a composite plating bath (the base bath $+2 \times 10^{-5} \mathrm{~mol} \mathrm{dm}^{-3}$ PA5000 $+2 \mathrm{~g} \mathrm{dm}^{-3}$ MWCNT) under galvanostatic conditions $5 \mathrm{~A} \mathrm{dm}^{-2}$ ) at $25^{\circ} \mathrm{C}$. The total electricity used for plating was $60 \mathrm{C} \mathrm{cm}^{-2}$. Although MWCNTs were incorporated in the deposited nickel, the surface morphology was very rough (Fig. 1a). Moreover, there were many voids or gaps in the deposit (Fig. 1b). We have already reported that metal-MWCNT composites fabricated by electrodeposition readily form powdery or void-rich composites, ${ }^{7}$ due to the electrical conductivity of MWCNTs along the axial direction. ${ }^{13}$ In order to form Ni-MWCNT composite films without voids and gaps, SA as a leveler and BD as a brightener $\left(0.01 \mathrm{~mol} \mathrm{dm}^{-3} \mathrm{SA}+2.5 \times 10^{-3} \mathrm{~mol} \mathrm{dm}^{-3} \mathrm{BD}\right)$ were added to the above plating bath. The effect of current density on the surface and cross-sectional morphology of the deposits was examined at $25^{\circ} \mathrm{C}$. Figure 2 shows the surface and cross-sectional SEM images of a Ni-MWCNT composite film electrodeposited under a current density of $5 \mathrm{~A} \mathrm{dm}^{-2}$. Compared to Fig. 1, the surface morphology is relatively smooth (Fig. 2a) and there are fewer significant voids or gaps in the film (Fig. 2b). Therefore, SA and BD are effective additives for the preparation of smooth and void-free $\mathrm{Ni}$ MWCNT composite films. Ni-MWCNT composite films with similar surface morphology and cross-sectional texture were obtained for a range of current densities from 1 to $5 \mathrm{~A} \mathrm{dm}^{-2}$. Figure 3 shows a comparison of cross-sectional SEM images of Ni-MWCNT composite films electrodeposited from the above composite plating bath 

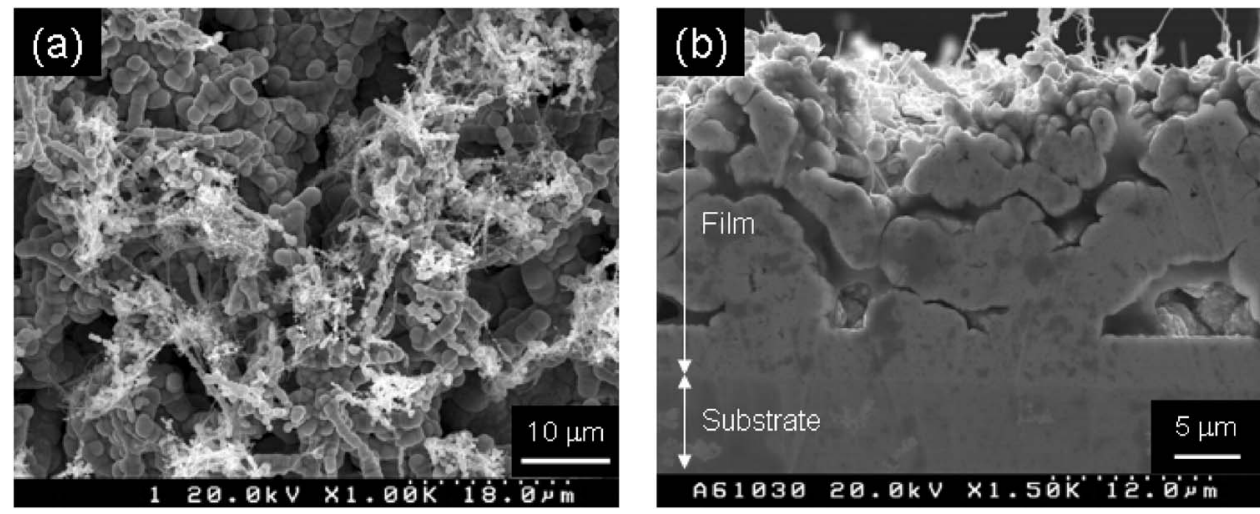

Figure 1. (a) Surface and (b) crosssectional SEM images of a Ni-MWCNT composite film. Bath composition: $1 \mathrm{~mol} \mathrm{dm}^{-3} \quad \mathrm{Ni}\left(\mathrm{SO}_{3} \mathrm{NH}_{2}\right)_{2}+0.5 \mathrm{~mol}$ $\mathrm{dm}^{-3} \quad \mathrm{H}_{3} \mathrm{BO}_{3}+2 \times 10^{-5} \mathrm{~mol} \mathrm{dm}^{-3}$ PA5000 $+2 \mathrm{~g} \mathrm{dm}^{-3}$ MWCNTs. Current density: $5 \mathrm{~A} \mathrm{dm}^{-2}$. Bath temperature: $25^{\circ} \mathrm{C}$.

under various current densities. The relatively large black regions in the SEM images are voids and the small black dots in the SEM images are the cross sections of MWCNTs. The number of voids tended to decrease with increasing current density. MWCNTs were homogeneously distributed in the nickel matrix under each current density and no gaps between MWCNTs and the nickel matrix were observed.

Figure 4 shows the effect of bath temperature on the crosssectional texture of the Ni-MWCNT composite films electrodeposited from the above composite plating bath at $5 \mathrm{~A} \mathrm{dm}^{-2}$. Significant voids and gaps increased with increasing bath temperature. It is thought that the effects of organic additives, such as the dispersing agent, on the morphology of composite films are changed by the bath temperature. The exact reason for this result is unknown. However, $25^{\circ} \mathrm{C}$ was found to be the best bath temperature for the preparation of void-free Ni-MWCNT composite films.

Figure 5 shows the relationship between the MWCNT concentration in the composite plating bath and the MWCNT content in the composite films. The content of MWCNTs increased with increasing MWCNT concentration in the composite plating bath in the range of MWCNT concentration from 0 to $2 \mathrm{~g} \mathrm{dm}^{-3}$. It was reasonably thought that the concentration of MWCNTs on the depositing cathode surface increased with increasing MWCNT concentration in the composite plating bath, which resulted in the increased incorporation of MWCNTs in the deposits. On the contrary, the content of deposited MWCNTs tended to decrease for plating bath concentrations over $2 \mathrm{~g} \mathrm{dm}^{-3}$. It was thought that the dispersion state of MWCNTs in the composite plating bath changed for MWCNT concentrations over $2 \mathrm{~g} \mathrm{dm}^{-3}$, and that MWCNTs might begin to condense at over $2 \mathrm{~g} \mathrm{dm}^{-3}$. This was confirmed by observation; therefore, it was concluded that at concentrations over $2 \mathrm{~g} \mathrm{dm}^{-3}$, the MWCNTs condense and formed large secondary aggregates, which results in the decrease of incorporation of MWCNTs in the deposits. Therefore, for internal stress measurements, deposits were prepared
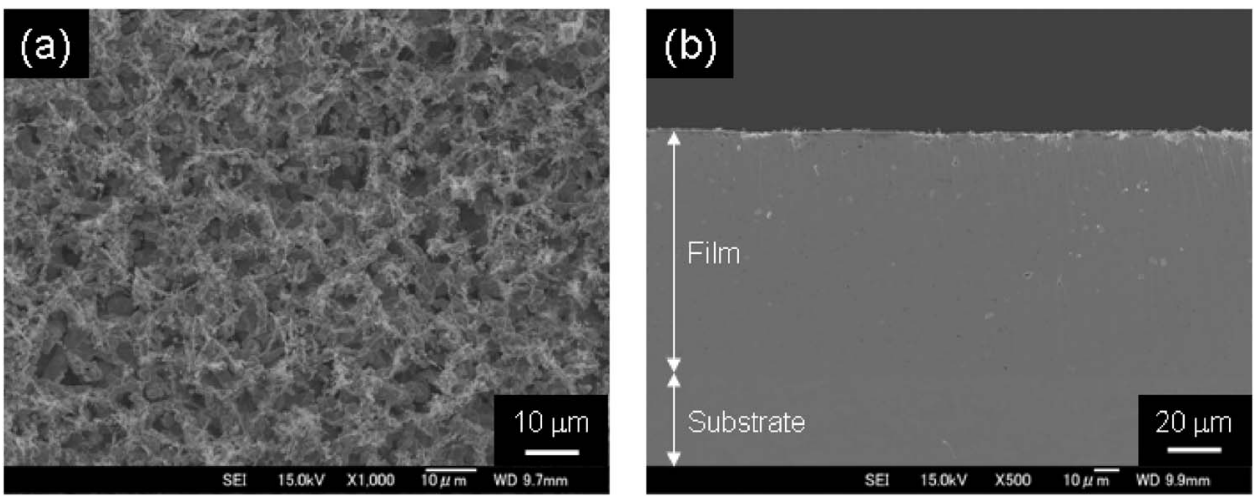

Figure 2. (a) Surface and (b) crosssectional SEM images of a Ni-MWCNT composite film. Bath composition: $1 \mathrm{~mol} \mathrm{dm}^{-3} \quad \mathrm{Ni}\left(\mathrm{SO}_{3} \mathrm{NH}_{2}\right)_{2}+0.5 \mathrm{~mol}$ $\mathrm{dm}^{-3} \mathrm{H}_{3} \mathrm{BO}_{3}+0.01 \mathrm{~mol} \mathrm{dm}^{-3} \mathrm{SA}+2.5$ $\times 10^{-3} \mathrm{~mol} \mathrm{dm}^{-3} \quad \mathrm{BD}+2 \times 10^{-5} \mathrm{~mol}$ $\mathrm{dm}^{-3} \quad$ PA5000 $+2 \mathrm{~g} \mathrm{dm}^{-3} \quad$ MWCNTs. Current density: $5 \mathrm{~A} \mathrm{dm}^{-2}$. Bath temperature: $25^{\circ} \mathrm{C}$.
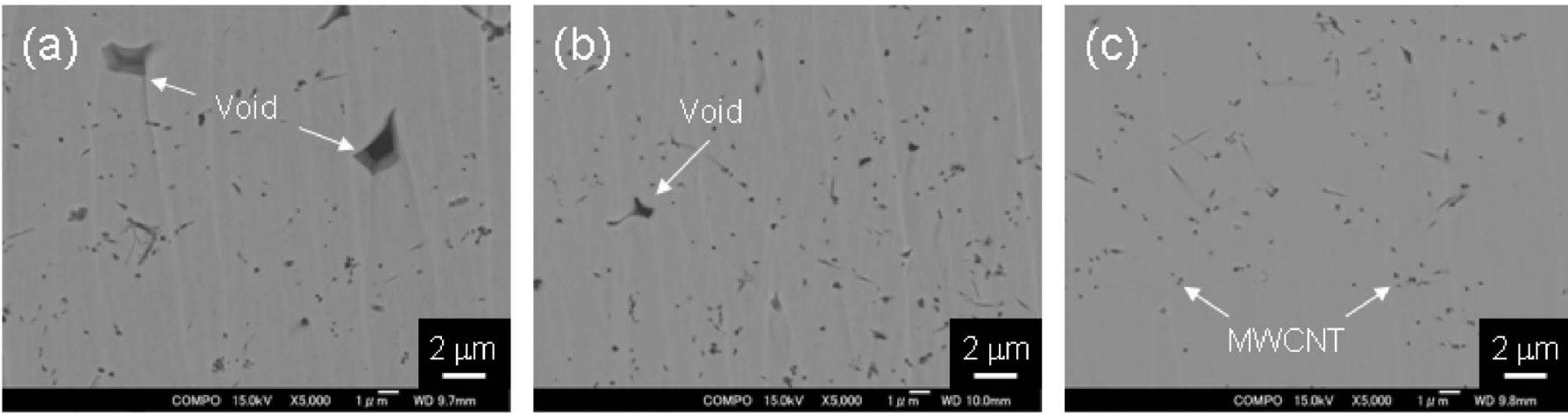

Figure 3. Cross-sectional SEM images of Ni-MWCNT composite films electrodeposited under various current densities: (a) 1 , (b) 3 , and (c) $5 \mathrm{~A} \mathrm{dm}^{-2}$. Temperature: $25^{\circ} \mathrm{C}$. Total electricity: $300 \mathrm{C} \mathrm{cm}^{-2}$. 

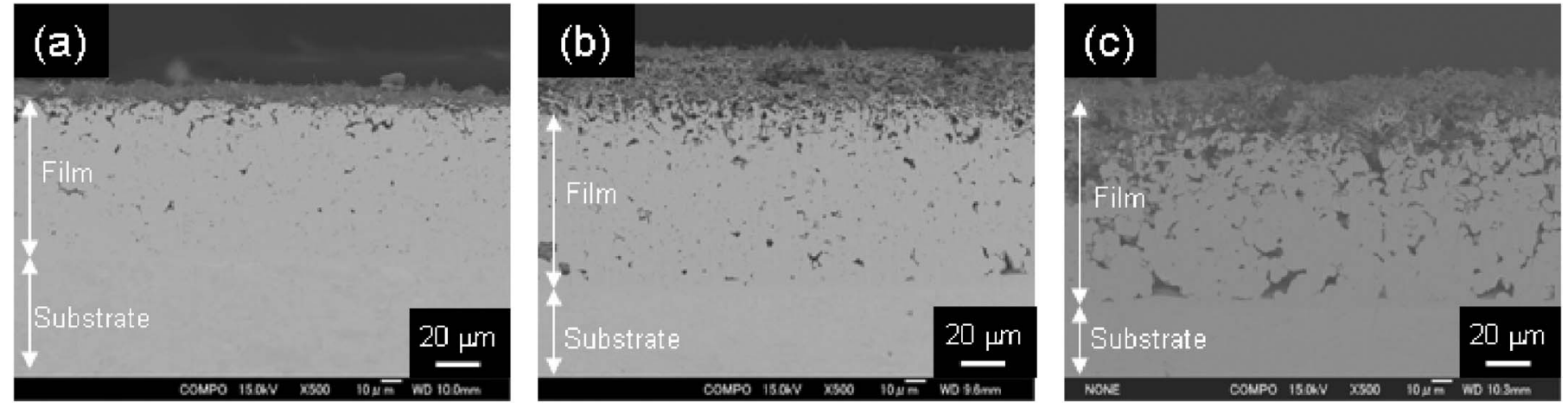

Figure 4. Cross-sectional SEM images of Ni-MWCNT composite films electrodeposited under various bath temperatures: (a) 25 , (b) 40 , and (c) $60{ }^{\circ} \mathrm{C}$. Current density: $5 \mathrm{~A} \mathrm{dm}^{-2}$. Total electricity: $300 \mathrm{C} \mathrm{cm}^{-2}$.

using a composite plating bath containing $2 \mathrm{~g} \mathrm{dm}^{-3}$ MWCNT at a bath temperature of $25^{\circ} \mathrm{C}$ and under a current density of $5 \mathrm{~A} \mathrm{dm}^{-2}$.

Tsuru et al. reported that the Ni films with low internal stress could be obtained from the sulfamate bath without chloride ions at $50^{\circ} \mathrm{C} .{ }^{14}$ Kelly et al. also reported that the stress-free Ni films could be obtained from a similar sulfamate bath at around $40^{\circ} \mathrm{C} .{ }^{15,16} \mathrm{In}$ this study, Ni film with low internal stress $\left(+0.35 \mathrm{~kg} \mathrm{~mm}^{-2}\right)$ was obtained at $40^{\circ} \mathrm{C}$. The positive or negative stress value indicates tensile or compressive stress, respectively. The internal stress of the Ni-MWCNT composite film electrodeposited from the composite plating bath was $-3.05 \mathrm{~kg} \mathrm{~mm}^{-2}$. Therefore, this Ni-MWCNT composite film had relatively large compressive stress. In order to reduce the internal stress of the Ni-MWCNT composite film, the effect of additive concentrations on internal stress was examined. Therefore, the effect of individual additives on the $\mathrm{Ni}$ film was investigated using the base plating bath.

Figure 6 shows the effects of the concentration of additives on the internal stress of nickel film plated from the sulfamate base bath at $25^{\circ} \mathrm{C}$. The tensile stress was increased with increasing concentration of PA5000. Internal stress could not be measured exactly in the range of PA5000 concentration over $1 \times 10^{-5} \mathrm{~mol} \mathrm{dm}^{-3}$ because the internal stress was too large. Thus, PA5000 tended to increase the internal tensile stress of the Ni film.

The tensile stress was decreased with increasing concentration of SA. Within the range of SA concentration examined, at approxi-

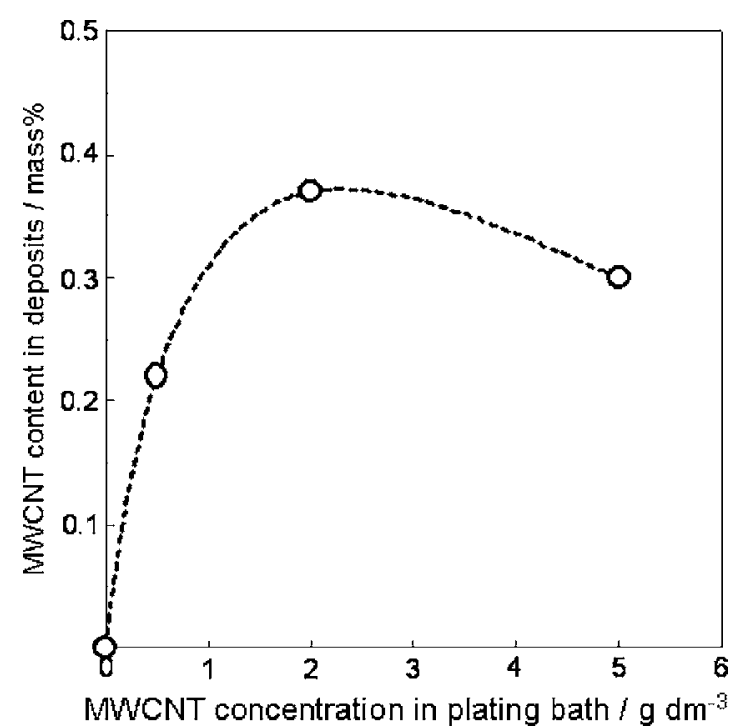

Figure 5. Relationship between the MWCNT concentration in the plating bath and the MWCNT content in the deposits. mately $1 \times 10^{-3} \mathrm{~mol} \mathrm{dm}^{-3}$, the internal stress changed from tensile to compressive. Thus, increasing the SA concentration tended to make the internal stress more compressive. The internal stress did not change significantly when varying the BD concentration. From these results, it was thought that the control of the PA5000 and/or SA concentrations would be effective in adjusting the internal stress of the nickel film. The effect of the SA concentration on the internal stress of Ni-MWCNT composite films was then investigated using the composite plating bath.

Figure 7 shows the effect of the SA concentration in the composite plating bath on the internal stress of Ni-MWCNT composite films. The internal stress changed from compressive to tensile with decreasing SA concentration, and the internal stress was almost zero at a SA concentration of $1 \times 10^{-3} \mathrm{~mol} \mathrm{dm}^{-3}$. Thus, a Ni-MWCNT composite film with low internal stress was electrodeposited from a bath with a composition of $1 \mathrm{~mol} \mathrm{dm}{ }^{-3} \mathrm{Ni}\left(\mathrm{SO}_{3} \mathrm{NH}_{2}\right)_{2}+0.5 \mathrm{~mol}$ $\mathrm{dm}^{-3} \mathrm{H}_{3} \mathrm{BO}_{3}+2 \times 10^{-5} \mathrm{~mol} \mathrm{dm}{ }^{-3} \mathrm{PA} 5000+1 \times 10^{-3} \mathrm{~mol}$ $\mathrm{dm}-3 \mathrm{SA}+2.5 \times 10^{-3} \mathrm{~mol} \mathrm{dm}-3 \mathrm{BD}+2 \mathrm{~g} \mathrm{dm}^{-3}$ MWCNTs and at a temperature of $25^{\circ} \mathrm{C}$ under a current density of $5 \mathrm{~A} \mathrm{dm}^{-2}$.

Figure 8 shows the cross-sectional SEM images of the NiMWCNT composite film electrodeposited from the above modified composite plating bath, which contains a lower concentration of SA, at $25^{\circ} \mathrm{C}$ under a current density of $5 \mathrm{~A} \mathrm{dm}^{-2}$. Although a few voids are present, the composite film was relatively compacted (Fig. 8a)

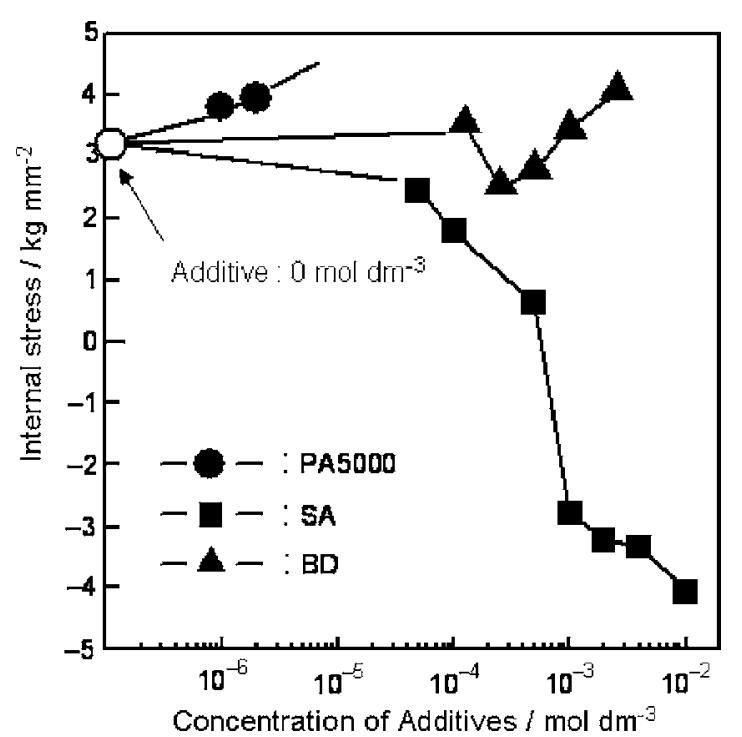

Figure 6. The effects of various additive concentrations on the internal stress of nickel films. Bath composition: $1 \mathrm{~mol} \mathrm{dm}^{-3} \mathrm{Ni}\left(\mathrm{SO}_{3} \mathrm{NH}_{2}\right)_{2}+0.5 \mathrm{~mol}$ $\mathrm{dm}^{-3} \mathrm{H}_{3} \mathrm{BO}_{3}+$ additives. 


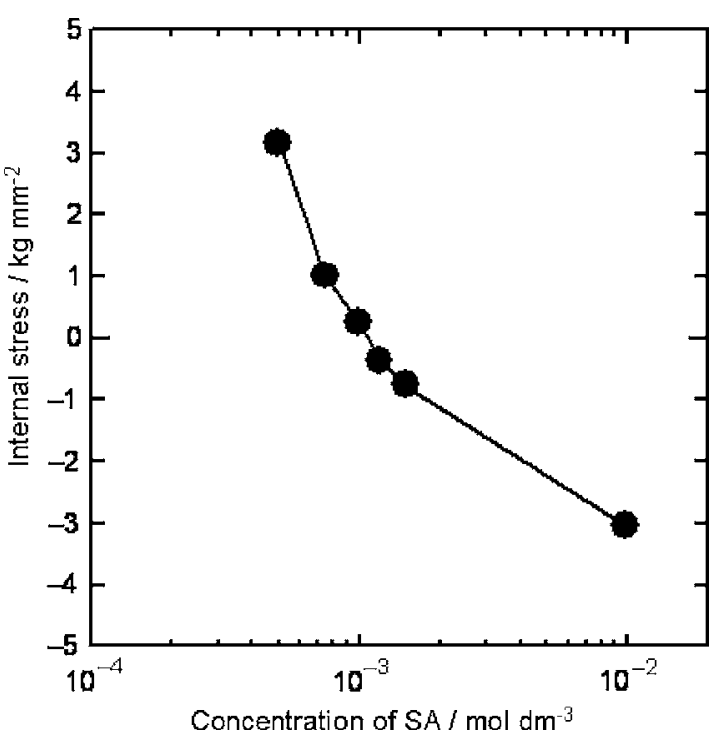

Figure 7. Effect of the concentration of SA on the internal stress of a NiMWCNT composite film.

and the MWCNTs were homogeneously dispersed throughout the film. The content of MWCNTs was approximately 0.4 mass $\%$.

\section{Conclusion}

Using an electrodeposition technique with a sulfamate bath, we have fabricated stress-free and relatively compacted Ni-MWCNT composite films with MWCNTs homogeneously dispersed throughout the nickel matrix.

\section{Acknowledgments}

This research was supported by the Cooperative Link of Unique Science and Technology for Economy Revitalization (CLUSTER) of the Ministry of Education, Culture, Sports, Science and Technology, Japan.

Shinshu University assisted in meeting the publication costs of this article.

\section{References}

1. A. Oberlin, M. Endo, and T. Koyama, J. Cryst. Growth, 32, 335 (1976).

2. S. Iijima, Nature (London), 354, 56 (1991).

3. X. H. Chen, J. C. Peng, X. Q. Li, F. M. Deng, J. X. Wang, and W. Z. Li, J. Mater Sci. Lett., 20, 2057 (2001).

4. X. H. Chen, C. S. Chen, H. N. Xiao, X. B. Liu, L. P. Zhou, S. L. Li, and G. Zhang, Tribol. Int., 39, 22 (2006).

5. L. Shi, C. F. Sun, P. Gao, F. Zhou, and W. M. Liu, Surf. Coat. Technol., 200, 4870 (2006)

6. X. H. Chen, C. S. Chen, H. N. Xiao, F. Q. Cheng, G. Zhang, and G. J. Yi, Surf. Coat. Technol., 191, 351 (2005).

7. S. Arai and M. Endo, Electrochem. Solid-State Lett., 7, C25 (2004).

8. S. Arai and M. Endo, Electrochem. Commun., 7, 19 (2005).

9. S. Arai and M. Endo, Electrochem. Commun., 5, 797 (2003).

10. S. Arai, M. Endo, and N. Kaneko, Carbon, 42, 641 (2004).

11. S. Arai, M. Endo, T. Sato, and A. Koide, Electrochem. Solid-State Lett., 9, C131 (2006).

12. M. Endo, CHEMTECH, 18, 568 (1988).

13. M. Endo, Y. A. Kim, T. Hayashi, Y. Fukai, K. Oshida, M. Terrones, T. Yanagisawa, S. Higaki, and M. S. Dresselhaus, Appl. Phys. Lett., 80, 1267 (2002).

14. Y. Tsuru, M. Nomura, and F. R. Foulkes, J. Appl. Electrochem., 32, 629 (2002).

15. J. J. Kelly, S. H. Goods, A. A. Talin, and J. T. Hachman, J. Electrochem. Soc., 153 C318 (2006).

16. S. H. Goods, J. J. Kelly, A. A. Talin, J. R. Michael, and R. M. Watson, J. Electrochem. Soc., 153, C325 (2006).
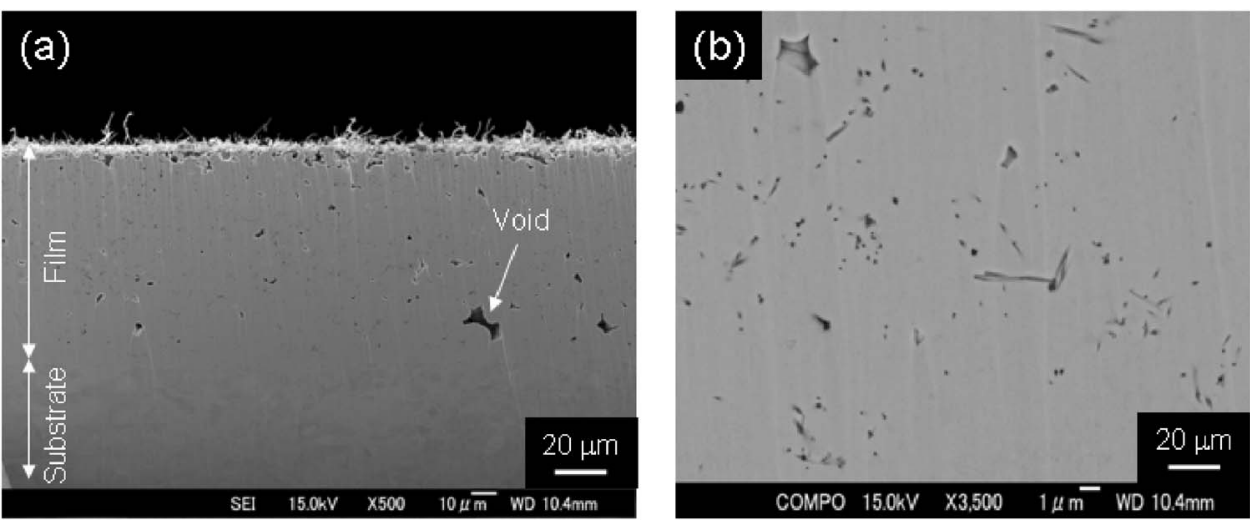

Figure 8. Cross-sectional SEM images of a Ni-MWCNT composite film with low internal stress: (a) low magnification and (b) high magnification. Total electricity: $300 \mathrm{C} \mathrm{cm}^{-2}$. 